JOURNAL OF ENGINEERING SCIENCES

ЖУРНАЛ ІНЖЕНЕРНИХ НАУК

ЖУРНАЛ ИНЖЕНЕРНЫХ НАУК

Web site: http://jes.sumdu.edu.ua

DOI: $10.21272 /$ jes.2017.4(2).h12

Volume 4, Issue 2 (2017)

UDC 519.252; 53.088.3; 629.3.01

\title{
Development of the method for estimating the inertia radius relative to the vertical axis of the car

\author{
Podrigalo M. A. ${ }^{1}$, Korobko A. I. ${ }^{2 *}$, Dubinin E. A. ${ }^{3}$, Tarasov Yu. V. ${ }^{3}$, Baytzur M. V. ${ }^{3}$
}

${ }^{1}$ Kharkiv P. Vasylenko National Technical University of Agriculture, 44 Alchevskih St., 61002, Kharkiv, Ukraine;

${ }^{2}$ L. Pogorilyy Ukrainian Scientific Research Institute of Forecasting and Testing of Machinery and Technologies for Agricultural Production, Kharkiv branch, 236 Velyko-Panasivska St., 61139, Kharkiv, Ukraine;

${ }^{3}$ Kharkiv National Automobile and Highway University, 25 Yaroslava Mudrogo St., Kharkiv, Ukraine

\author{
Article info: \\ Paper received: \\ The final version of the paper received: \\ Paper accepted online:
}

November 4, 2017

December 3, 2017

December 4, 2017
*Corresponding Author's Address:

ak82andrey@gmail.com

\begin{abstract}
The method of estimating the inertia radius relative to the vertical axis of the car is proposed. This allows a third to reduce the relative error of its definition. A refined formula for calculating the radius of inertia design with respect to the vertical axis of the car is proposed. The use of the proposed formula reduces the error of determining the radius of inertia from $21-27 \%$ to $5 \%$, and the error of determining the inertia moment for the car from $46-$ $61 \%$ to $10 \%$. A method for assessing the adequacy of the results of theoretical and experimental studies is proposed. The use of the method has shown that the refined formula for calculating the radius of inertia relative to the vertical axis of the car makes it possible to reduce the probability of mismatching the results up to three times.
\end{abstract}

Keywords: moment of inertia, radius of inertia, error, car, method, methodical error, mismatch of results.

\section{Introduction}

The inertia moment relative to the vertical axis substantially affects the handling and stability of the car. At the design stage of the car methods for determining the inertia moment relative to the vertical axis not accurate enough. The test stand is difficult to determine the inertia moment need to design. Probabilistic methods to calculate the inertia radius relative to the vertical axis of the car propose by different authors. More than $30 \%$ is error for the probabilistic method. The inertia radius has degree two in the formula the inertia moment.

In this article, a method for estimating the inertia radius relative to the vertical axis of the car was offered. It is based on the results of experimental studies are known. This reduces the methodological error in three times.

The task is to determine the inertia moment relative to the vertical axis for the car in the design phase occurs. The inertia moments and position of centre of mass have a significant effect on stability and handling for the car. The center of mass is characterized by horizontal coordinates and vertical coordinates of the car. The coordinates of the center of mass in the design are determined by graphical and analytical method.
The essence of the method. The essence of the method. Find on the drawing the relative position of the center of mass for each unit or item of the car. To find its distance to a particular axis. Find its distance to a particular axis. The horizontal coordinate $b$ for the center of mass of the car (from rear axle) can be found by the following formula:

$$
b=\frac{G_{1} x_{1}+G_{2} x_{2}+G_{3} x_{3}+\ldots+G_{\mathrm{i}} x_{\mathrm{i}}}{G_{\mathrm{a}}}=\sum_{i=1}^{n} q_{\mathrm{i}} x_{\mathrm{i}}
$$

where $G_{a}$ - the weight of the car, N; $G_{1}, G_{2}, G_{3}, G_{i}-$ the weight individual components of car that, are used in the determination of the position of its center of mass; $q_{i}$ - the relative weight of the $i$-th unit;

$$
q_{\mathrm{i}}=\frac{G_{\mathrm{i}}}{G_{\mathrm{a}}}
$$

$x_{1}, x_{2}, x_{3}, x_{i}$ - the shoulders of the moments of forces of attraction for the elements of the car relative, to the rear axle; $n$ - the number of elements which are taken into account when calculating the center of mass of the last.

The location of the other centre of mass for the car is determined similarly. 
The question arises. Graphical and analytical method is used to assess the inertia moment relative to the vertical axis of the car.

The obvious is that

$$
\sum_{i=1}^{n} G_{\mathrm{i}}\left(x_{\mathrm{i}}-b\right)=0
$$

The inertia moment relative to the vertical axis of the car is found as

$$
I_{c z}=\sum_{i=1}^{n} \frac{G_{\mathrm{i}}}{g}\left(x_{\mathrm{i}}-b\right)^{2}+\sum_{i=1}^{n} \frac{G_{\mathrm{i}}}{g} i_{z i}^{2}
$$

where $i_{z i}$ - the inertia radius relative to the vertical axis of the car the $i$-th element, m; $g$ - acceleration of gravity, $\mathrm{g}=9,81 \mathrm{~m} / \mathrm{s}^{2}$.

It is impossible to determine $I_{\mathrm{zc}}$ using the graphical and analytical method. It is difficult to determine $i_{z i}$.

In the paper [1], a probabilistic method is proposed for finding the inertia radius relative to the vertical axis of the car. In the present paper, the formula there exists

$$
i_{z}=\sqrt{\frac{1}{2} a b+\frac{B^{2}}{12} \pm \frac{1}{6} a b}
$$

where $a$ - the projection of the distance from the front axle to the center of mass of the car for the horizontal plane, $\mathrm{m} ; B$ - automobile track, $\mathrm{m}$.

The authors built a probabilistic model in [2]. The displacement of the centers of mass of the car parts from the front axle and the rear axle in the transverse direction was taken into account. The formula was updated

$$
i_{z}=\sqrt{\left(\frac{1}{2} \pm \frac{1}{6}\right)\left(a b+\frac{B^{2}}{4} \frac{b}{a}\right)}
$$

The results of the experimental determination for the inertia moments and the inertia radius are relative to the vertical axis of the car in [3]. The results are shown for the ten models in Table 1.

In Table 2 estimation of the relative error for determining the mathematical expectation of the inertia radius relative to the vertical axis of the car are shown. The inertia radius relative to the vertical axis defined by the formulas (5) and (6) (in comparison with the experimental results [3]).

The results are shown in Table 2 were established. The relative error for the determination of the inertia radius relative to the vertical axis $i_{\mathrm{z}}$ by the formula (5) is in the range to14.3-36 \%, and according to the revised formula (6) is to $6.83-34.25 \%$.

Let us define the expression to calculate the error of the inertia moment relative to the vertical axis $I_{\mathrm{zc}}$. It is necessary to relate the error of determining the inertia radius relative to the vertical axis $i_{\mathrm{z}}$ and the inertia moment relative to the vertical axis $I_{\mathrm{zc}}$

$$
\begin{aligned}
& \delta I_{z c}=\frac{\Delta I_{z c}}{I_{z c}}=\frac{m_{\mathrm{a}} i_{z}^{2}-m_{\mathrm{a}} \bar{i}_{z}^{2}}{m_{\mathrm{a}} i_{z}^{2}}=1-\frac{\bar{i}_{z}^{2}}{i_{z}^{2}}= \\
& =1-\frac{\left(i_{z} \pm \Delta i_{z}\right)^{2}}{i_{z}^{2}}=\frac{\Delta i_{z}^{2}}{i_{z}^{2}} \mp 2 \frac{\Delta i_{z}}{i_{z}^{2}}=\delta i_{z}^{2} \mp 2 \delta i_{z} .
\end{aligned}
$$

where $\Delta I_{\mathrm{z}}, \Delta i_{\mathrm{z}}-$ the absolute error in the determination $i_{\mathrm{z}}$ and $I_{\mathrm{zc}}$, respectively.

Table 1 - The results experimental determination of the inertia moments and the inertia radius relative to the vertical axis $O Z$ of the car

\begin{tabular}{|c|c|c|c|c|c|c|c|c|c|c|}
\hline \multirow{2}{*}{ The parameters } & \multicolumn{10}{|c|}{ The cars } \\
\cline { 2 - 12 } & $\mathrm{A}$ & $\mathrm{B}$ & $\mathrm{C}$ & $\mathrm{D}$ & $\mathrm{E}$ & $\mathrm{F}$ & $\mathrm{G}$ & $\mathrm{H}$ & $\mathrm{I}$ & $\mathrm{J}$ \\
\hline$m_{a}, \mathrm{~kg}$ & 2119 & 2590 & 2178 & 883 & 2050 & 1010 & 795 & 628 & 824 & 1167 \\
\hline$I_{\mathrm{zc}}, \mathrm{kg} \mathrm{m}^{2}$ & 4571 & 6327 & 5435 & 1099 & 5444 & 1030 & 1050 & 481 & 1020 & 2099 \\
\hline$i_{\mathrm{z}}, \mathrm{m}$ & 1.469 & 1.563 & 1.579 & 1.115 & 1.629 & 1.009 & 1.149 & 0.875 & 1.113 & 1.341 \\
\hline$a, \mathrm{~m}$ & 1.470 & 1.680 & 1.500 & 0.900 & 1.490 & 1.240 & 1.322 & 0.863 & 1.368 & 1.148 \\
\hline$b, \mathrm{~m}$ & 1.530 & 1.350 & 1.550 & 1.280 & 1.700 & 1.020 & 0.958 & 1.167 & 1.012 & 1.552 \\
\hline$L, \mathrm{~m}$ & 3.000 & 3.030 & 3.050 & 2.180 & 3.200 & 2.260 & 2.280 & 2.030 & 2.380 & 2.700 \\
\hline$h, \mathrm{~m}$ & 0.500 & 0.500 & 0.500 & 0.400 & 0.500 & 0.450 & 0.473 & 0.421 & 0.421 & 0.510 \\
\hline$B, \mathrm{~m}$ & 1.470 & 1.485 & 1.570 & 1.280 & 1.568 & 1.107 & 1.117 & 0.995 & 1.166 & 1.323 \\
\hline
\end{tabular}

Table 2 - Comparison of results for calculation by formulas (5) and (6)

\begin{tabular}{|c|c|c|c|c|c|c|c|c|c|c|}
\hline \multirow{2}{*}{ The parameters } & \multicolumn{10}{|c|}{ The cars } \\
\cline { 2 - 12 } & $\mathrm{A}$ & $\mathrm{B}$ & $\mathrm{C}$ & $\mathrm{D}$ & $\mathrm{E}$ & $\mathrm{F}$ & $\mathrm{G}$ & $\mathrm{H}$ & $\mathrm{I}$ & $\mathrm{J}$ \\
\hline$i_{\mathrm{z}}, \mathrm{m}$ & 1.469 & 1.563 & 1.579 & 1.115 & 1.629 & 1.009 & 1.149 & 0.875 & 1.113 & 1.341 \\
\hline $\bar{i}_{z}, \mathrm{~m}(5)$ & 1.142 & 1.148 & 1.170 & 0.844 & 1.213 & 0.857 & 0.859 & 0.766 & 0.897 & 1.018 \\
\hline $\bar{i}_{z}, \mathrm{~m}(6)$ & 1.186 & 1.164 & 1.217 & 0.931 & 1.272 & 0.871 & 0.864 & 0.819 & 0.904 & 1.089 \\
\hline$\delta\left(\bar{i}_{z}\right), \%(5)$ & 28.63 & 36.16 & 35.01 & 32.09 & 34.29 & 17.73 & 33.82 & 14.30 & 24.01 & 31.17 \\
\hline$\delta\left(\bar{i}_{z}\right), \%(6)$ & 23.86 & 34.25 & 29.75 & 19.73 & 28.10 & 15.86 & 33.01 & 6.83 & 23.07 & 23.10 \\
\hline
\end{tabular}


The largest error $\delta i_{\mathrm{zc}}$ when the lower sign on the right side of expression (7). In this case, when $\delta i_{z}=0.35$ value $\delta I_{\mathrm{zc}}=0.82$. In this case, when $\delta i_{\mathrm{z}}=0.35$ value $\delta I_{\mathrm{zc}}=0.82$. Because it creates more than $80 \%$ of the error to determine the inertia moments relative to the vertical axis $\delta I_{\mathrm{zc}}$.

The range of variation of the random variable $i_{\mathrm{z}}$, adopted in [1, 2], is big. Therefore, a large error for a probabilistic method to determine the inertia radius is relative to the vertical axis of the car.

The purpose of the study: improving the accuracy of measurement the inertia radius relative to the vertical axis of the car at the design stage.

To achieve this goal it is necessary to solve the following tasks:

- to offer the calculated dependence, which will allow, at the design stage of the car, to increase the accuracy of determining the inertia radius relative to the vertical axis;

- to assess the adequacy of calculation results to experimental results.

\section{Results}

\subsection{The calculated dependence for determining the inertia radius relative to the vertical axis of the car}

Experimental determination of the inertia radius relative to the vertical axis of the car $i_{\mathrm{z}}$ is shown in Table 1 . Analysis of the results shows the following. The value $i_{\mathrm{z}}$ is close to the results of the calculation for the inertia radius relative to the vertical axis according to the formula

$$
\overline{i_{z}}=\sqrt{a b}
$$

The value $i_{\mathrm{z}}$ is the mean quadratic value of the coordinate $a$ and coordinate $b$ the center of mass of the car. It should be said. Formula (8) was determined by E. A. Chudakov [4] and the following researchers $[1,5,6]$. It is a condition of ensuring the lateral stability of the rear axle of the car at corner entry and exit.

The results of the calculation by the formula (8) given for ten models (those that are shown in Table 1) in Table 3 are shown. The calculated values and the experimental results [3] are compared among themselves.

Shows the following for analysis of the results (given in Table 3). Value of the difference absolute theoretical values and experimental values for the inertia radius relative to the vertical axis of the car calculated by the formula (8) does not exceed $15 \%$. If we ignore the error for car $\mathrm{F}$ and car $\mathrm{H}$. Other 8 cars $\left|\delta i_{\mathrm{z}}\right|$ does not exceed $6 \%$. Given the measurement errors of the inertia radius relative to the vertical axis of the car, for cars A, B, C, D, E, G, I, J, the accuracy of determining the moment of inertia $I_{\mathrm{zc}} 12 \%$ does not exceed. For car $\mathrm{F} \delta I_{\mathrm{zc}}=24 \%$ and $32 \%$. For car $\mathrm{H}-\delta I_{\mathrm{zc}}=31.33 \%$.

To sum up. The accuracy of the calculations increases when the mathematical expectation of the inertia radius relative to the vertical axis of the car about a vertical axis is used equation (8). The average relative error decreases from $21-27 \%$ to $5 \%$ compared to the calculations on (5) and (6), which was used earlier. This means that the average error of determination for the inertia moments relative to the vertical axis of the car decreased from 46 $61 \%$ to $10 \%$.

Table 4 shows the calculation results for the ratio in the ten car models that were considered. The average value determined.

The average value of the absolute value is the value 0.063 , as shows the analysis of the calculation results (Table 4).

S. Litvinov in [5] says: the study of stability and control may be greatly simplified; the inertia radius relative to the vertical axis of the car must be determined in the square, through the product $a b$, that is, by using the relations (8). M. Julien [7] and A. S. Dobrin [8, 9] did the same. In the paper [5] with reference to the results of the study [6], data characterizing the limits of the relationship for passenger cars different classes. The inertia radius relative to the vertical axis of the car expresses the following relationship

$$
\overline{i_{z}}=A \sqrt{a b}
$$

where $A$ - the factor correction that is determined from the ratio

$$
A=\frac{i_{z}}{\sqrt{a b}}
$$

In Table 5 shows the values of the parameter $A$ obtained for ten models are given in Table 1.

The parameter $A$ in 42 implementation (given in [5] and Table 5) for estimation of the average value can be used. Two of the car's load (specified in [5]) as the implementation can be used.

As a result, define

$$
A=\bar{A} \pm \sigma_{A}=0,925 \pm 0,065
$$

where $\sigma_{A}-$ the standard deviation of the parameter $A$.

The calculated value of the inertia radius relative to the vertical axis of the car $i_{z p}$ within one standard deviation can be determined by the formula

$$
A=\bar{A} \pm \sigma_{A}=0,925 \pm 0,065
$$

The moment of inertia $I_{\text {zcp }}$ relative to the vertical axis of the car estimated value

$$
A=\bar{A} \pm \sigma_{A}=0,925 \pm 0,065
$$

To convert the expression (13)

$$
I_{z c p}=m_{a} 0,860 a b \pm m_{a} 0,120 a b=\bar{I}_{z c p} \pm 0,120 m_{a} a b
$$

where $\bar{I}_{z c p}$ - the average value of inertia moment relative to the vertical axis of the car

$$
\bar{I}_{z c p}=0,860 m_{a} a b
$$


Table 3 - Comparison of calculation results by formula (8) and the results of the experiment [3]

\begin{tabular}{|c|c|c|c|c|c|c|c|c|c|c|}
\hline \multirow{2}{*}{ Parameters } & \multicolumn{10}{|c|}{ The cars } \\
\hline & $\mathrm{A}$ & $\mathrm{B}$ & $\mathrm{C}$ & $\mathrm{D}$ & $\mathrm{E}$ & $\mathrm{F}$ & $\mathrm{G}$ & $\mathrm{H}$ & $\mathrm{I}$ & $\mathrm{J}$ \\
\hline$i_{\mathrm{z}}, \mathrm{m}$ & 1.469 & 1.563 & 1.579 & 1.115 & 1.629 & 1.009 & 1.149 & 0.875 & 1.113 & 1.341 \\
\hline$\overline{i_{z}} \cdot \mathrm{m}$ & 1.500 & 1.620 & 1.525 & 1.073 & 1.591 & 1.125 & 1.125 & 1.003 & 1.177 & 1.334 \\
\hline$\Delta i_{\mathrm{z}} \cdot \mathrm{m}$ & -0.032 & -0.057 & 0.054 & 0.042 & 0.038 & -0.116 & 0.024 & -0.128 & -0.064 & 0.007 \\
\hline$\delta i_{\mathrm{Z}} \cdot \%$ & 2.17 & 3.6 & -3.4 & -3.8 & -2.3 & 11.5 & -2.1 & 14.6 & 5.7 & 0.52 \\
\hline$\delta I_{\mathrm{zc}} \cdot \%$ & 4.39 & 7.33 & 6.92 & 7.74 & 4.65 & 24.32 & 4.24 & 31.33 & 11.72 & 1.04 \\
\hline
\end{tabular}

Table 4 - Results to determine value

\begin{tabular}{|c|c|c|c|c|c|c|c|c|c|c|}
\hline \multirow{2}{*}{ Parameters } & \multicolumn{10}{|c|}{ The cars } \\
\hline & $\mathrm{A}$ & $\mathrm{B}$ & $\mathrm{C}$ & $\mathrm{D}$ & $\mathrm{E}$ & $\mathrm{F}$ & $\mathrm{G}$ & $\mathrm{H}$ & $\mathrm{I}$ & $\mathrm{J}$ \\
\hline$\overline{i_{z}} \cdot \mathrm{m}$ & 1.500 & 1.620 & 1.525 & 1.073 & 1.591 & 1.125 & 1.125 & 1.003 & 1.177 & 1.334 \\
\hline$\Delta i_{\mathrm{z}} \cdot \mathrm{m}$ & -0.032 & -0.057 & 0.054 & 0.042 & 0.038 & -0.116 & 0.024 & -0.128 & -0.064 & 0.007 \\
\hline$\left|\frac{\Delta i_{z}}{\overline{i_{z}}}\right|$ & 0.021 & 0.035 & 0.035 & 0.039 & 0.024 & 0.103 & 0.021 & 0.128 & 0.054 & 0.005 \\
\hline$i_{\text {zmax }} \cdot \mathrm{m}$ & 1.594 & 1.722 & 1.621 & 1.140 & 1.691 & 1.196 & 1.196 & 1.066 & 1.251 & 1.419 \\
\hline$i_{\text {zmin }} \cdot \mathrm{m}$ & 1.405 & 1.518 & 1.429 & 1.005 & 1.491 & 1.054 & 1.054 & 0.940 & 1.102 & 1.250 \\
\hline$i_{\mathrm{z}} \cdot \mathrm{m}$ & 1.468 & 1.563 & 1.579 & 1.115 & 1.629 & 1.009 & 1.149 & 0.875 & 1.113 & 1.341 \\
\hline average value & \multicolumn{10}{|c|}{0.063} \\
\hline
\end{tabular}

Table 5 - The parameter $A$

\begin{tabular}{|c|c|c|c|c|c|c|c|c|c|c|}
\hline \multirow{2}{*}{ Parameters } & \multicolumn{10}{|c|}{ The cars } \\
\cline { 2 - 12 } & $\mathrm{A}$ & $\mathrm{B}$ & $\mathrm{C}$ & $\mathrm{D}$ & $\mathrm{E}$ & $\mathrm{F}$ & $\mathrm{G}$ & $\mathrm{H}$ & $\mathrm{I}$ & $\mathrm{J}$ \\
\hline$i_{\mathrm{z}} \cdot \mathrm{m}$ & 1.469 & 1.563 & 1.579 & 1.115 & 1.629 & 1.009 & 1.149 & 0.875 & 1.113 & 1.341 \\
\hline$\sqrt{a b} \cdot \mathrm{m}$ & 1.500 & 1.620 & 1.525 & 1.073 & 1.591 & 1.125 & 1.125 & 1.003 & 1.177 & 1.334 \\
\hline$A$ & 0.979 & 0.965 & 1.035 & 1.039 & 1.024 & 0.897 & 1.021 & 0.872 & 0.946 & 1.005 \\
\hline
\end{tabular}

The error relative in determining $I_{\text {zcp }}$ within the standard deviation of the inertia radius $i_{\mathrm{z}}$

$$
\delta I_{z c p}= \pm \frac{m_{a} a b}{\bar{I}_{z c p}}= \pm \frac{0,12 m_{a} a b}{0,86 m_{a} a b}= \pm 0,139
$$

Data analysis ([5] and Table 5) following. Only 13 implementations outside the interval out of the 42 . This is 1 standard deviation of the inertia radius relative to the vertical axis of the car.

\subsection{Assessing the adequacy of results for theoretical and experimental studies}

The results for theoretical and experimental research are random variables. Make assumption. The data is distributed according to the normal law. We use the quantile for normal distribution of the composition of two random variables - inertia radius for experimental and theoretical

$$
u_{p}=-\left|\frac{\bar{i}_{z \mathrm{e}}-\bar{i}_{\mathrm{zp}}}{\sqrt{\sigma_{\mathrm{e}}^{2}+\sigma_{\mathrm{p}}^{2}}}\right|
$$

where $\bar{i}_{z \mathrm{e}}, \bar{i}_{\mathrm{zp}}-$ the average value of the inertia radius, defined by experimental and calculated, respectively; $\sigma_{e}, \sigma_{p}-$ average quadratic error of definition $i_{\mathrm{ze}}$ and $i_{\mathrm{zp}}$, respectively.

Table 6 shows the calculation of the quantile up and the probability of a discrepancy between the results of theoretical studies and experimental studies for 10 model car the inertia radius relative to the vertical axis, are given in Table 1.

The calculated value of the standard deviation the inertia radius of the car to the vertical axis

$$
\sigma_{p}=0,065 \sqrt{a b}
$$


Table 6 - Assessing the adequacy of the results for determination the inertia radius of the car to the vertical axis, a theoretical way and experimental way

\begin{tabular}{|c|c|c|c|c|c|c|c|c|c|c|}
\hline \multirow{2}{*}{ Parameters } & \multicolumn{10}{|c|}{ The cars } \\
\hline & $\mathrm{A}$ & $\mathrm{B}$ & $\mathrm{C}$ & $\mathrm{D}$ & $\mathrm{E}$ & $\mathrm{F}$ & $\mathrm{G}$ & $\mathrm{H}$ & I & $\mathrm{J}$ \\
\hline $\bar{i}_{z \mathrm{e}}, \mathrm{m}$ & 1.469 & 1.563 & 1.579 & 1.115 & 1.629 & 1.009 & 1.149 & 0.875 & 1.113 & 1.341 \\
\hline$\overline{\bar{i}_{z \mathrm{p}}, \mathrm{m}}$ & 1.387 & 1.498 & 1.411 & 0.992 & 1.472 & 1.041 & 1.041 & 0.928 & 1.089 & 1.234 \\
\hline$u_{\mathrm{p}}$ & -0.421 & -0.309 & -0.847 & -0.882 & -0.759 & -0.219 & -0.738 & -0.406 & -0.157 & -0.617 \\
\hline$p$ & 0.660 & 0.620 & 0.800 & 0.810 & 0.760 & 0.580 & 0.770 & 0.655 & 0.560 & 0.730 \\
\hline
\end{tabular}

\section{Conclusions}

The proposed revised the formula to calculate the inertia radius of the car to the vertical axis at the design stage. which is the result of the study. Using the proposed formula allows to reduce the error in determining the inertia radius from $21-27 \%$ to $5 \%$.
The accuracy of determining the inertia moment of the car is reduced from $46-61 \%$ to $10 \%$.

Method for assessing the adequacy of results of theoretical studies and experimental studies. offered by us. showed the following. Using the refined formula for calculating $i_{\mathrm{z}}$ reduces the likelihood of a mismatch results three times.

\section{References}

1. Podrigalo. M. A.. Volkov. V. P.. Kyrchatyi. V. Y.. \& Boboshko. A. A. (2003). Manevrennost' i tormoznye svojstva kolyosnykh mashyn [Maneuverability and Brake Properties of Wheeled Cars]. KhNADU. Kharkiv [in Ukrainian].

2. Podrigalo. M. A.. Dubinin. E. A.. \& Glushhenko. V. V. (2015). Utochneniye veroyatnostnogo metoda opredeleniya radiusov inercii kolesnoj mashyny [Clarification of the probabilistic method for determining the radii of inertia of a wheeled car]. Automobile transport. Collection of scientific works. No. 37. 116-122 [in Russian].

3. Ellis. D. R. (1975). Upravlyaemost' avtomobilya [Driving ability of the car]. Moscow. Mashynostroyeniye [in Russian].

4. Chudakov. E. A. Ustojchivost' avtomobilya pri zanose [Stability of a car with a skidding]. AN SSSR [in Russian].

5. Litvinov. A. S. (1971). Upravlyaemost' i ustojchivost' avtomobilya [Controlability and stability of the automobile]. Moscow. Mashynostroyeniye [in Russian].

6. Mitschke. M. (1960). Fahrtrichtung und Fahrstabilitat Vor vierradrigen Kraftfahrzeugen. Deutsche Kraftfahrtforshung. pp. 135 [in Deutschland].

7. Julien. M. A. (1955). Etude analytique de la stabilite de routedes voitures automobiles. SJA. No. 4 [in Italian].

8. Dobrin. A. S. (1966). Issledovaniye dvizheniya avtomobilya po zadannoj traektorii [Investigation of the motion of a car in a given trajectory]. Proceedings of the workshop on controllability and stability of the car. No. 1. [in Russian].

9. Dobrin. A. S. (1968). Ustojchivost' i upravlyaemost' avtomobilya pri neustanovivshemsya dvizhenii [Stability and controllability of a car with non-steady motion]. Automobile industry. No. 9. 23-27 [in Russian].

10. Podrigalo. M.. Isakova. O.. \& Korobko. A. (2017). Novyy sposib otsinyuvannya zbihu rezul'tativ teoretychnykh i eksperymental'nykh doslidzhen' [A new scientific approach to evaluating the results of research on theoretical and experimental]. Metrology and instruments. Scientific and production journal. Vol. 5 (67). 48-51 [in Ukrainian]. 